the night and forenoon. Up to twelve noon, he continued in the same state; quite unconscious, the pupils widely dilated, no sensation in the conjunctiva, or anywhere else ; and could not stallow. At this time, mustard poultices were put on the back of the neck and the calves of the legs, and his lips were wetted at intervals with brandy.

Shortly after this, slight twitchings of the facial muscles were observed, and he swallowed a drop or two of brandy placed on the back of his tongue. Next he responded to a pinch on the arm, and, in a little more time, he began to move his legs. When his mother spoke to him, he tried to open his eyes, but failed. Movements of his legs, and also of his head, now became frequent; and it was evident that these were caused by the mustard. On being spoken to, ho mumbled a reply. Up to this time his breath smelt strongly of chloroform.

At 1.30 P.M. I left him, and did not see him again until 9.30 P.M. when I learned that he had been able to walk about the room a little, but was very dazed all the afternoon. He was lying on a sofa, sleep. ing heavily, and his breath still smelling strongly of chloroform. I spoke to him, and shook him gently, but did not rouse him. On Monday he was very sick, and vomited often, and mplained of severe pain in the stomach. On Tuesday the sicknwr, vomiting, and pain continued, but were not so severe. On Wednerday; he onIy complained of weakness, and since then he has gradually recovered strength, and is now quite well.

\section{A CASE OF DIAPHRAGMATIC EMPYEMA.}

By C. J. CULLINGWORTH, M.D., M.R.C.P.,

Physician to Bt. Mary's Hospital, Manchester; Professor of Obstetrics and Gynæecology at the Owens College, Victoria University.

THE very interesting communication on a case of diaphragmatic empyema by Dr. Vincent $D$. Harris, in the Journal for May 22nd, in. duced me to look up my notes of the following case, which I saw a few years ago in consultation with my friend, Dr. J. R. Woodcock, then of Knutsford, in Cheshire, and which, though it was made the subject of a short paper read at a Branch meeting of the Association, has not hitherto been published.

A Cheshire farmer, aged 61, had for some months been seized, from time to time, while at work, with severe pain in the right side, incapacitating him for a few hours on each occasion. About two months before I saw him, he had been thrown from a mowing-machine, receiving a bruise on the shoulder. When just recovering from the effects of this accident, he had an attack of nausea and vomiting, writh some febrile disturbance lasting several days. During this attack, and about a fortnight before my visit, he was suddenly taken very ill while on the commode. Dr. Woodcock was sent for, and found him cold and collapsed, lying with his knees flexed, and complaining of intense pain across the abdomen. From this condition, the patient unexpectedly rallied, though he continued for some days to be too ill for a satisfactory examination to be made.

On October 8th, 1880, Dr. Woodcock and I saw him together. $\mathrm{He}$ had a worn and emasiated appearance, and lay on his back, careful to avoid the slightest movement. He had no cough or expectoration the breathing was a little hurried, the pulse quick, the temperature in the axilla $99.3^{\circ} \mathrm{Fahr}$., the tongue red and furred, the bowels constipated. The right side of the chest was absolutely dull on percussion, anteriorly, from the upper border of the fourth rib downwards, and posteriorly from the spine of the scapula to the base. The breathsounds were inaudible over the dull area; above it, on the same side, respiration was bronchial. Change of position made no alteration in the signs. The left lung was resonant throughout, and its sounds normal. The heart's a pex could be seen and felt beating half an inch to the left of the nipple, and on a level with it. The heart-sounds were feeble and irregular, but otherwise normal. The abdomen was tympanitic, but not much distended; its parietes were rigid, and everywhere tender on pressure, especially over the epigastrium. The right lobe of the liver did not reach below the ribs; the left lobe ex. tended to within an inch of the umbilicus.

A few hours after our visit, the patient was seized, for the first time, with an attack of coughing, and this was followed by the expectoration of a little foetid pus. These symptoms continued up to the patient's death, on October 12th.

At the necropsy, made on October 13th, by Dr. Woodcock and myself, there was found, on the right side of the chest. 2 broad band of adhesion running along the outer border of the lung continuonsly trom the base nearly to the apex, and then passing backwards to the vertebral column. On breaking through this, and passing the hand behind the lung, a quantity of serous fluid was found, containing a large clot of coagulated lymph. This fluid had been rigidly confined by a boundary line of firm adhesions. On removing the lung, about a pint of fotid pus was found lying between the diaphragm and the base of the lung. The margin of the lung was adherent to the diaphragm all round, so that the abscess could not have been reached from the chest-wall at any point without piercing lung-tissue. In the pleurs lining the arched roof of this cavity, there was an ulcer, equal in size to a shilling, which had perforated the lung. In the centre of the ulcer was an open bronchial tube, with jagged edges, and filled with pus. On section, other tubes in the same lobe were seen to be similarly filled with pus. The upper lobe of the right lung was less crepitant than it should be, and exuded, on section, an abundance of frothy serum, slightly blood-stained. The left lung was healthy, and free from adhesions. The heart was firmly adherent to the pericardium over a considerable part of its surface, both before and behind. The liver was normal in size, and hyperæmic. It was matted to all the tissues around it, and especially to the diaphragm, by very firm adhesions. The other abdominal viscera were healthy.

\section{SURGICAL MEMORANDA.}

\section{CASE OF OPERATION IN HYDATID DISEASE OF THE} LIVER.

Mrs. C., the wife of a sea-captain, observed an enlargement of the right side, in the region of the liver. On examination, the bulging was found to be very considerable, so as quite to alter the symmetry of the figure. Under the impression that it was due to a hydatid cyst, the needle of a hypodermic syringe was introduced; and some clear non-albuminous fluid drawn off, the operation being followed by the usual appearance of some spots of urticaria.

On January 12th, 1883, an incision, about two inches long, was made in the most prominent part of the swelling, through the integument and down to the cyst. This was packed with iodoform gauze, and-was dressed over this with carbolic gauze.

On January 19th, the cyst was opened, about a pint of fluid, with a good deal of blood, escaping. A tube was placed in the cyst, and a dressing of carbolic gauze laid over it. The operation was followed by another eruption of urticaria. Both operations and the subsequent dressings were conducted under the carbolic spray. The cyst gradually shrank; and, in the beginning of May, the patient was able to accompany her husband upon a voyage; but the wound did not perfectly heal till the middle of June. It may be worthy of remark that the lady was accustomed to fondle a lap-dog.

In a short article on Operation in Hydatid Disease of the Liver. which appeared in the JouRNal of May 8th, it is related that Korach did six of his cases by the method originally advocated by Volckmanu, in which the incision through the integument and cyst-wall is done iu two stages; and that all of these were successful. This case is recorded simply as another example of the same operation, with a like result.

E. Hooper MaY, F.R.C.S., Tottenham.

\section{OBSTETRIC MEMORANDA.}

\section{a CASE OF SPONTANEOUS EXPULSION OF A FEMALE FETUS.}

ON Sunday, June 13th, I was called to see Mrs. L., aged 39. I founl the patient in strong labour, and, upon examination, discovered that the shoulder presented; the liquid amnii had all drained away, and the uterus firmly contracted upon the foetus. After some time, the uterine action, to a great degree, abated, and I endeavoured to turn, but with a negative result.

As the patient was in a very delicate state of health (being the sub. ject of advanced phthisis, complicated with valvular disease of th heart), and the uterine action became now more marked, I determine I that some radical measure must be resorted to. The presence of the fotus in the uterus appeared to act banefully on the patient's condition, for great weakness supervened. I resolved now to perform embryulcia, but was delighted to find a prolonged and severe uterine pain, resulted in the arm and shoulders being thrust into the vagina then, resting on the peringum for a few seconds, was, with a superhuman effort, expelled beyond the vulva. It appeared now difficult 